\section{An interactive FORTRAN IV program for calculating power, sample size, or detectable differences in means}

\section{WILLIAM P. DUNLAP \\ Tulane University, New Orleans, Louisiana 70118}

In designing experiments, the question of power arises in at least three common forms. The most common question asked is (1) "How many subjects must I have in each group?" A more sophisticated form of the power question is (2) "If there are real differences among the populations sampled, what is the probability that I will find the differences significant?" The answer to the second question is defined as the power of an experiment. Perhaps the most sophisticated expression of the power question is (3) "Given my experimental design, what size differences am I likely to find significant?" Answers to the above questions are not simple, since power is controlled by four basic parameters: (1) sample size, (2) alpha level, (3) population variance, and (4) actual differences that exist between the population means of the groups. To calculate a value for any of the above factors at a given power, or to calculate power itself, the remaining parameters must be fixed. For example, to answer the first question regarding necessary sample size, one must supply values for alpha, power, population variance, and the actual differences to be detected among the populations. Thus any computation regarding power depends on being able to make reasonable estimates of important aspects of the experiment in question.

Cohen (1977) points out that the almost universal neglect of power planning by researchers is due in large part to the relative inaccessibility of the necessary tables and techniques, which are scattered throughout the statistical literature, and the mathematical sophistication required to use these materials. Even Cohen's simplified tables require some calculation, and interpolation is often necessary for practical problems.

To perform power calculations, the present program queries the user for the necessary information, providing alternate forms of input when possible. By changing the values of input parameters within reasonable limits, the researcher can quickly put together a picture of the power characteristics of the planned research.

The program first asks for the number of groups and the alpha level. The user is then asked to estimate his anticipated mean square error (this can often be done from a previous ANOVA on a similar experiment or pilot study). If the mean square error is not known, the program requests the estimated population standard deviation. The user then selects which of the three questions he wants answered. If, for example, sample size is to be computed, the user is asked to supply expected group means. If this cannot be done, the range between the largest and smallest means is requested. If no response is given, or if the user was unable to estimate the error term or standard deviation earlier, the range between means in standard deviation units is required. Last, the desired power is entered and the program displays the necessary sample size. Other options, if selected, are approached in a similar interactive manner.

This program has proved helpful in a number of ways. First, when trying to advise researchers regarding the power aspects of their projects, it is difficult to explain that power calculations are complex. The researcher usually feels that there should be a simple answer to "What $\mathrm{n}$ do I need?" On the other hand, if the researcher sits in front of a CRT, then the complexities of power become immediately obvious. It becomes clear that one must have considerable knowledge regarding the planned research to assess power with reasonable accuracy. The program is also quite valuable in teaching students in statistics courses how power works. Finally, the program allows the user to plan his/her research, and since the program is interactive, there is no need for instruction manuals or tables.

Power is calculated using the following approximate formula from Zelen and Severo (1965, p. 948):

$$
\begin{aligned}
& z= \\
& \frac{\left[d_{1} F /\left(d_{1}+\lambda\right)\right]^{1 / 3}\left[1-2 /\left(9 d_{2}\right)\right]-\llbracket 1-2\left(d_{1}+2 \lambda\right) /\left[9\left(d_{1}+\lambda\right)^{2}\right] \rrbracket}{\llbracket 2 / 9\left(d_{1}+2 \lambda\right) /\left(d_{1}+\lambda\right)^{2}+2 /\left(9 d_{2}\right)\left[d_{1} /\left(d_{1}+\lambda\right) F\right]^{2 / 3} \rrbracket^{1 / 2}},
\end{aligned}
$$

where $d_{1}$ and $d_{2}$ are the numerator and denominator degrees of freedom, respectively, $F$ is the critical value from the central $F$ distribution at the stated alpha level, and $\lambda$ is the noncentrality parameter. This formula is coded as FUNCTION POW. In order to use this function, one must know the critical value of $F$, given alpha and the degrees of freedom. The critical $F$ value is calculated by FUNCTION CVF, which converges on the desired value within six decimal places using FUNCTION FPRB, which computes probabilities associated with F ratios (Dunlap \& Duffy, 1975). The probability of the standard normal deviate, $z$, is then computed by FUNCTION ZPRB, also described by Dunlap and Duffy (1975). In order to calculate necessary sample size, the program uses FUNCTION POW repeatedly to obtain increasingly better estimates of the required sample size, converging on the integral value that will produce power equal to or greater than that requested. The calculation of group means detectable at a given power is also done iteratively, although the convergence is quite rapid.

Requirements. The computational portions of the program are written in single-precision FORTRAN IV, 
and run on a DEC-2060 computer. Since the program is interactive, it is designed to run with a CRT terminal for input and output. Although pains were taken to avoid using DEC-specific FORTRAN statements, a few nonstandard features were included in the input statements to make the program run conveniently on the DEC system. First, the user will probably have to modify the statement assigning logical units if the program is to be run on computers other than DEC. Second, the symbol " $\$$ " in READ statements causes the cursor to remain at the end of a line on the CRT and thus is cosmetic but not necessary. Last, the asterisk in place of a FORMAT statement number allows free format input on the DEC system.
Availability. A listing of the program may be obtained at no cost from William P. Dunlap, Department of Psychology, Tulane University, New Orleans, Louisiana 70118.

\section{REFERENCES}

CoHen, J. Statistical power analysis for the behavioral sciences. New York: Academic Press, 1977.

Dunlar, W. P., \& DufFY, J. A. FORTRAN IV functions for calculating exact probabilities associated with $\mathrm{z}$, chi-square, $\mathrm{t}$, and F values. Behavior Research Methods \& Instrumentation, 1975, 7, 59-60.

Zelen, M., \& Severo, N. C. Probability functions. In M. Abramowitz \& I. A. Stegun (Eds.), Handbook of mathematical functions. New York: Dover, 1965.

Appendix

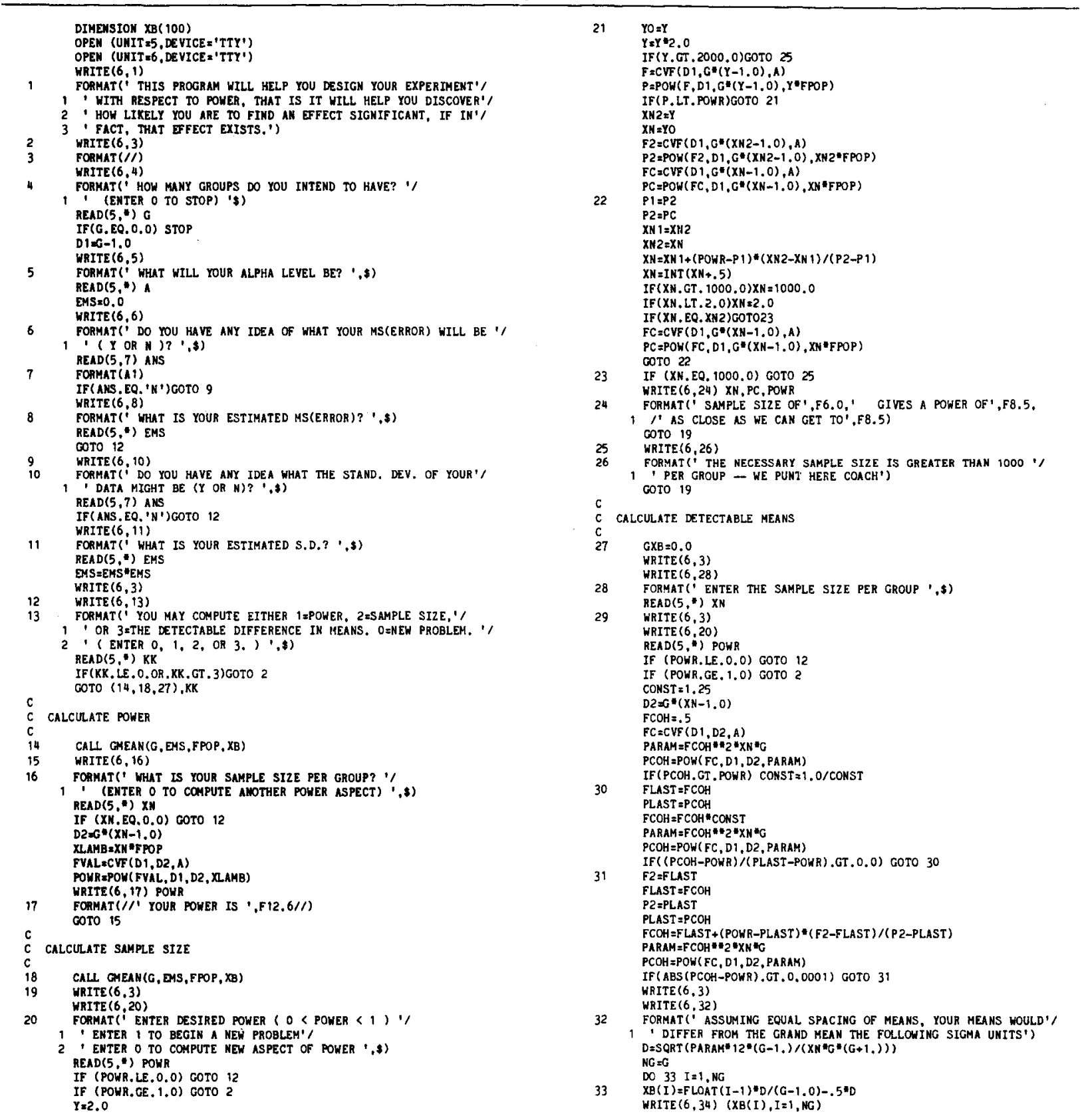


FORMAT ( $1 X, 6 F$ 12.3)

WRITE $(6,35)$ D

35 FORMAT (' THE RAMGE OF MEANS IN SIGMA UNITS IS ',F12.3)

IF (EMS. EQ. 0.0) GOTO 29

$S D=S O R T$ (EMS)

WRITE $(6,36)$ SD

36 FORMAT (' YOUR WTYHIN GROUP STANDARD DEVIATION IS ASSIRED',

1 TO $\mathrm{BE} \cdot, \mathrm{F} 12.3)$

If $($ GXB.EO.0.0) GOTO 38

IFITE $(6,37)$ GXB

37 FORMAT (' YOUR GRAND MEAN IS ASSUMED to BE '.FI2.3)

COTO 40

COTO 40

39 GORMAT(' ERTER a VALUE FOR YOUR GRAND MEAN '. (1)

READ $(5, *) \mathrm{GXB}$

IF (GXB, EQ, 0.0) GoTo 29

40 DO $41 I=1, N G$

$41 \quad X B(I)=X B(I) " S D+G \times B$

WRITE $(6,42) \quad(X B(I), I=1$, MG)

42 FORMAT(' DETECTABLE MEANS MIGH' BE'/1X, $\left.\left(6 F_{12} 12.2\right)\right)$

RAMGE $=X B($ HG $)-X B(1)$

RAHGE $=X B($ HG $)-X B(1$
WRITE $(6,43)$ RANGE

43 FORMAT (' WITH A RAHGE OF',F 12.3 )

FORMAT ('

END TO

C SUBROUTINE GMEAN -- INPUTS GROUP MEANS \& FINDS $F$ VALUE

c

SUBROUTINE CMEAN(G, EMS, FPOP, XB)

DIMENSION XB(1)

NG $=G$

IF (EMS, EQ, O, O. OR, EMS, EQ, 1,0) GOTO 10

HAITE $(6,1)$

1 FORMAT(II' DO YOU HAVE APPBOXIMATE VALUES FOR YOUR EXPECTED

I GROUP MEANS? ( $Y$ OR $N$ ) I

READ(5.2) ANS
FOAMAT

READ $(5,2)$ ANS
FORMAT(A1)

IF (ANS.EQ. 'N') GOTO 4

HRITE $(6,3)$

FORMAT (' ENTER MEANS PLEASE')

READ (5,") (XB(I), I=1, MG)

COTO 13

4 HRITE $(6,5)$

5 FORMAT ( $'$ CAN YOU GIVE AN APPROXIMATE RANGE FOR YOUR GROUP $"$

- MEANS IN TERMS OF RAW DATA ( $Y$ OR N)? ', 5 )

AEAD(5, 2) ANS

IF (ANS.EQ.' 'N') GOTO 8

IF (ANS. EQ.

6 FORMAT ( $i$ ENTER SMALLEST AND LARGEST MEANS')

FORMAT (" ENTER

READ $(5, ") X S, X L$
XINC $=(X L-X S) /(G=1$.

$X I N C=(X L-X S)$

$A A A=I-1$

$X B(I)=X S+A A A * X I N C$

COTO 13

8 WRITE $(6,9)$

9 FORMAT(' TO ALLOW FURTHER PROGRESS YOUR MS(ERROR) HAS'

' BEEN SET EQUAL TO 1.0')

EMS $=1,0$

EMS $=1,0$

FORMAT( $($ PLEASE ENTER THE RANGE BETWEEN YOUR LARGEST AND'

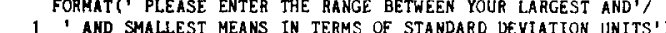

READ SMALLEST
READ 5 ") RANG

XINC $=$ RANG $/(\mathrm{G}-1,0)$

DO $12 \quad I=1$, NG

$A A A=I-1$

$12 \quad X B(I)=A A A * X I N C$

$S S B=0.0$

$T B=0.0$

DO $14 \quad I=1$, NG

$\mathrm{TB}=\mathrm{TB}+\mathrm{XB}(\mathrm{I})$

$S S B=S S B+X B(I) \times X B(I)$

14 CONTINUE

CONTINUE
$S S B=S S B-T B$
TROP

$S S B=S S B-T B-T B$
$F P O P=S S B / D S$

RETURN

RETURN

C FUNCTION CVF - FINDS CRITICAL F VRLUES

FUNCTION CVF (D1,D2,A)

$\mathrm{F} 2=3$,

$F=7$,

PL 2=FPRB (3..D1,D2)

PL $2=A L O G(P L 2)$

$P E=F P R B(7 \ldots D 1 . D 2)$

$P L X=A L O G(A)$

$\mathrm{F} 1=\mathrm{F} 2$

$F 2=F$
$P L 1=P L 2$

$P L 2=A L O G(P E)$

$F=F 1+(P L X-P L 1) \cdot(F 2-F 1) /(P L 2-P L 1)$

IF (F.LE. 0.0) $F=1.0$

$P E=F P R B(F, D 1, D 2)$

IF(ABS (PE-A).GT, .000001)GOTO ;

$C V F=F$

RETURI

c

C FUNCTION FPRB - FINDS PROBABILITY OF F-ZRLUES

FUNCTION FPRB(FR, DFN, DFD)

C COMPUTES PROBABILITY OF F-RATIO (FR) WITH OFM \& DFD DEGREES OF
C FREEDOM (INTEGRAL OF F FROM FR TO INF INITY)

IF (FR"DFN"DFD. LE. O.0) STOP

$F=F B$

$A=D F N$

$B=D F D$

INV $=0$

IF (AMOD $(A, 2,0)$. EO, O, 0)GOTO 1

IF $(A M O D(B, 2,0)$. NE. 0.0$)$ GOTO 4

$F=1.0 / F$

$A=D F D$

$B=D F A$

IN $V=1$

$Q=A^{*} F /\left(A^{*} F+B\right)$

$Q L=A L O G(Q)$

$F P R B=0.0$

$C=A L O G(1,0-0) * B / 2,0$

$\operatorname{IF}(C, G T,(-E)) F P R B=E X P(C)$

$\operatorname{IF}(A, E Q, 2,0)$ GOTO 3

$N=A / 2,0-1,0$

$R=0.0$

DO $2 \quad I=1, N$

$\mathrm{X}=\mathrm{I} * 2$

$X=I+A$
$R=R+A(B+X-2,0)-A \operatorname{LOG}(X)+Q L$

$S=R+C$

$I F(S . G T .(-E)) F P R B=F P A B+E X P(S)$

2 CONTINUE

3 IF (INV.EQ. 1)FPRB $=1.0-E P R B$

RETUR:

$P I=3.1415927$

$Q=A * F /(A * F+B)$

$S A=S O R T(O)$

$S A L=R L O S(S A)$

$C A=\$ Q R T(1.0-Q)$

CAL $=A L O G(C A)$

$A L=A S I N(S A)$

$F P R B=1.0-2.0 * \mathrm{AL} / \mathrm{PI}$

IF (B.EQ $, 1,0)$ GOTO 0

$C=A L O G(2.0 \div S A / P I)$

FPRB $=F P R B-E X P(C+C A L)$

IF (B. EQ. 3.0)GOTO 6

$\mathrm{N}=(\mathrm{B}-3.0) / 2.0$

DO $5 \mathrm{I}=1$,

$X=2 * I+1$

$R=R+A \operatorname{LOG}((X-1,0) / X)$

$S=R+C A L * X+C$

$S=R+C A L A X+C$
IF $(S, G T,(-E)) F P R B=F P R B-E X P(S)$

5 CONTINUE

IF (A. EQ. 1, O) RETURN

$\operatorname{IF}(A$

IF $(B, G T, \uparrow, 0) C=C+A L O G(B-1,0)$

$C=C+A L O E(2.0 / P I)+S A L+C A L B$

$I F(C . G T .(-E)) F P R B=F P R B+E X P(C)$

IF(A, EQ. 3. O)RETURN

$M=(A-3.0) / 2.0$

$R=0,0$

$D T^{7} I=1, N$

$R=R+A \operatorname{LOC}((B+X-2.0) / X)$

$S=R+S A L *(X-1.0)+C$

IF (S.GT. (-E))FPRB $=F P R B+E X P(S)$

CONTINUE

RETUA

END

C FUNCTION POW - APPROXIMATE POWER CALCULATIONS

FUNCTION POW(F,D1, D2, XL)
$A=(D 1 * F /(D 1+X L)) *(1,13)$

$A=(D) F /(D)+X L)$

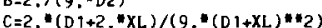

$\left.C=2 . *(D)+2, * X L) /(9 . *(D)+X L) * A^{*}\right)$
$X=(1,-B) \rightarrow 1,+C) / S Q R T\left(C+B^{*} A^{*} A\right)$

$P O W=2 P R B(X)$

RETUR

FUNCTION ZPRB - PROBRBILITY OF STAND. NORM. DEVIATE

FUNCTION ZPRB( 2

C COMPUTES 1-TATLED PROBABILITY OF STARDARD NORMAL DEVIATE

C (INTEGRaL OF MORMaL CURVE FROM $Z$ TO INF IMITY)

$x=2$
IF $(2$, LT, 0.0) $X=-2$

IF
ZPRB

ZPRB $=1.0$
IF $(X . G T \cdot 5.612)$ GOTO

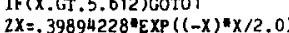

$2 X=.39894228 * E X P((-X) * X / 2$
$T=1.0 /(1.0+.2316419 * X)$

$B=.31938153^{\circ} \mathrm{T}$

TT $=T$ *T

$8=\mathrm{B}-.356563782 * \mathrm{TT}$

$T T=T T^{* T}$

$B=B+1.781477937 * T T$

$\Pi T=T^{*} \mathrm{~T}$

$B=B-1.821255978 * T T$

$\mathrm{TT}=\mathrm{TT} T$

$B=B+1,330274429=T$ T

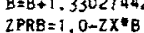

IFRB $=1.0-Z X+B$
IF $(2, G T, 0.0) Z P R B=1.0-Z P R$

IF $(2 . G T, 0.0) Z P R B=1.0-2 P R$

RETUR 